Article

\title{
Picrasma quassioides (D.DON) Benn. Ethanolic Extract Improves Atopic Dermatitis and Hyperactivity Disorder in DNCB-Treated BALB/c Mice
}

\author{
Min-Jin Choi, Ly Thi Huong Nguyen (D), Heung-Mook Shin * and In-Jun Yang *(D)
}

Citation: Choi, M.-J.; Nguyen, L.T.H.; Shin, H.-M.; Yang, I.-J. Picrasma quassioides (D.DON) Benn. Ethanolic Extract Improves Atopic Dermatitis and Hyperactivity Disorder in DNCB-Treated BALB/c Mice. Appl. Sci. 2022, 12, 2032. https://doi.org/ 10.3390/app12042032

Academic Editor: Jongsung Lee

Received: 3 February 2022

Accepted: 11 February 2022

Published: 16 February 2022

Publisher's Note: MDPI stays neutral with regard to jurisdictional claims in published maps and institutional affiliations.

Copyright: (C) 2022 by the authors. Licensee MDPI, Basel, Switzerland. This article is an open access article distributed under the terms and conditions of the Creative Commons Attribution (CC BY) license (https:// creativecommons.org/licenses/by/ $4.0 /)$.
Department of Physiology, College of Korean Medicine Dongguk University, Gyeongju 38066, Korea; zzz9924@dongguk.ac.kr (M.-J.C.); nguyenthihuongly_t58@hus.edu.vn (L.T.H.N.)

* Correspondence: heungmuk@dongguk.ac.kr (H.-M.S.); injuny@dongguk.ac.kr (I.-J.Y.); Tel.: +82-54-770-2372 (H.-M.S.); +82-54-770-2366 (I.-J.Y.)

\begin{abstract}
Atopic dermatitis (AD) is a chronic inflammatory skin disorder that can be associated with psychiatric disorders. Picrasma quassioides (D.Don) Benn (Gomokpi, GMP), a traditional medicinal herb, has been used to treat skin diseases, including AD. The current study examined the effects of an ethanolic extract of GMP on 2,4-dinitrochlorobenzene (DNCB)-induced AD mice. The severity of skin symptoms and behavioral changes in AD mice were evaluated. GMP alleviated the AD-like skin inflammation and hyperlocomotion activity in DNCB-treated BALB/c mice. The effects of GMP behavioral abnormalities might occur by inhibiting TNF- $\alpha$ production in the PFC. GMP suppressed the production of TARC (Th2 chemokine) in TI-stimulated HaCaT keratinocytes. Moreover, GMP also exerted immunosuppressive effects by reducing TNF- $\alpha$ production in LPS-stimulated Raw264.7 macrophages, IL-17 expression in PI-stimulated EL4 cells, and VEGF secretion in SP-stimulated HMC-1 cells. These findings suggest that GMP could be useful for treating AD by modulating inflammatory responses and comorbid behavioral changes.
\end{abstract}

Keywords: Picrasma quassioides (D.Don) Benn.; atopic dermatitis; skin inflammation; ADHD; neuroinflammation

\section{Introduction}

Atopic dermatitis (AD) is a common inflammatory skin disease that requires longterm treatment because of its frequent recurrence [1]. Typical AD manifestations include dryness, redness, swelling, and severe itching. The pathogenesis of AD is unclear, but genetic factors, environmental factors, and immune system imbalance are associated with the cause of AD [2-4]. Upon the invasion of external allergens into the body, the balance of T helper (Th) 1 and Th2 cytokines is disrupted, resulting in the overproduction of Th2 cytokines and stimulation of B cells to produce IgE [2]. IgE can bind to Fc epsilon receptor 1 (FcERI) on the mast cell surface, leading to mast cell degranulation and the secretion of inflammatory mediators, such as histamine, cytokines, chemokines, and growth factors [5]. These degranulation substances cause and worsen AD symptoms, such as swelling and itching [6]. The interaction between immune cells and keratinocytes plays a crucial role in skin inflammatory responses in AD. Keratinocytes are the major component of the epidermis that can produce various cytokines and chemokines to recruit immune cells, such as T cells, macrophages, eosinophils, and mast cells, into lesional skins [7]. In turn, the inflammatory mediators produced by these immune cells can promote cytokine production and decrease the expression of skin barrier peptides in keratinocytes, leading to skin inflammation and barrier disruption in AD lesions [8].

Several psychiatric comorbidities have been indicated in patients with AD [9]. A previous study reported that AD is associated with an increased risk of attention deficit hyperactivity disorder (ADHD) in both children and adults, with a higher risk in those 
with more severe symptoms of $\mathrm{AD}$ and frequent sleep disturbances [10]. The possible underlying mechanisms for the higher prevalence of psychiatric disorders in $\mathrm{AD}$ patients have been suggested [11]. The persistent excessive release of inflammatory cytokines in $\mathrm{AD}$ affects the development of brain areas, such as the prefrontal cortex (PFC) and neurotransmitter system, which play crucial roles in ADHD [12]. Hyperactivity patterns, decision-making, and attention deficits in ADHD are associated with the PFC region, and clinical studies have shown changes in neuronal activity in the PFC region after chronic AD [13,14]. Elevated levels of pro-inflammatory molecules, such as TNF- $\alpha$, IFN- $\gamma$, and IL10 in AD lead to the dysregulation of the hypothalamus-pituitary-adrenal (HPA) axis and the secretion of corticosteroids, which might contribute to the development of ADHD [15]. This suggests a close relationship in the pathophysiology of AD and psychiatric disorders. Thus, therapeutic approaches that manage AD symptoms and psychological disorders should be investigated to improve the patients' satisfaction with AD treatment.

Picrasma quassioides (D.Don) Benn. bark, also known as Gomokpi (GMP) in traditional Korean, can strengthen the stomach, eliminate dampness, remove intestinal parasites, and promote pus discharge. GMP has been used to treat several symptoms, such as indigestion, gastroenteritis, pulmonary tuberculosis, and eczema $[16,17]$. The main components of GMP are quassinoids, triterpenoids, and alkaloids, which have a range of pharmacological effects, including anti-inflammatory, anti-cancer, and neuroprotective effects [18]. Previous studies reported that the GMP extract inhibited the allergic response in an ovalbumin-induced mouse model of asthma and suppressed the production of inflammatory mediators in RAW264.7 macrophages stimulated with lipopolysaccharide (LPS) $[19,20]$. Hence, this study investigated the beneficial effects of GMP on skin symptoms and behaviors in a 2,4-dinitrochlorobenzene (DNCB)-induced mouse model of AD.

\section{Materials and Methods}

\subsection{Chemicals and Reagents}

Iscove's Modified Dulbecco's Medium (IMDM) was purchased from (Merck Millipore, Darmstadt, Germany), and high glucose Dulbecco's modified Eagle's medium (DMEM) was obtained from (Welgene Inc., Gyeongsangbuk, Korea). Fetal bovine serum (FBS) and penicillin-streptomycin were acquired from (Invitrogen, Carlsbad, CA, USA). Substance $\mathrm{P}$ (SP), 2,4-dinitrochlorobenzene (DNCB), lipopolysaccharide (LPS), and dexamethasone (DEX) were purchased from (Sigma-Aldrich, St. Louis, MO, USA). The mouse VEGF, TNF- $\alpha$, IFN- $\gamma$, IL-1 $\beta$, IL-6, IL-17, and human VEGF ELISA kits were purchased from (Koma Biotech, Seoul, Korea). Human MDC and TARC ELISA kits were supplied by (R\&D Systems, Minneapolis, MN, USA). Tissue extraction reagent I was obtained from (ThermoFisher Scientific, Carlsbad, CA, USA).

\subsection{Preparation of Herbal Ethanolic Extracts of Picrasma quassioides (D.Don) Benn. Bark}

Picrasma quassioides (D.Don) Benn. bark (GMP) was provided and verified by Professor Heung-Mook Shin (Department of Physiology, Dongguk University). The dried GMP (204 g) was extracted in $70 \%$ ethanol at $80^{\circ} \mathrm{C}$ for $3 \mathrm{~h}$. The fluid extract was passed through $0.2 \mathrm{~mm}$ filter paper (Whatman, Maidstone, UK), evaporated with a rotary vacuum evaporator, and freeze-dried for three days. The yield of GMP was $4.47 \%$. The GMP extract was stored at $-20^{\circ} \mathrm{C}$ for further experiments.

\subsection{High-Performance Liquid Chromatography (HPLC) Analysis}

Picrasin B and quassin were obtained from (ChemFaces, Wuhan, China). The chemical constituents were analyzed by an HPLC system (1290 series, Agilent, Santa Clara, CA, USA). The GMP extract and standard samples were separated on a Kinetex C18 column $(4.6 \times 250 \mathrm{~mm}, 5 \mu \mathrm{m}$, Phenomenex) with two mobile phases: (A) $0.1 \%$ phosphoric acid and (B) acetonitrile. The solvent gradient was 10-90\% (B) for $25 \mathrm{~min}$, followed by $5 \mathrm{~min}$ equilibration. The column was kept at $35^{\circ} \mathrm{C}$ with a flow rate of $0.9 \mathrm{~mL} / \mathrm{min}$. Picrasin $\mathrm{B}$ 
and quassin were detected at $210 \mathrm{~nm}$ and $254 \mathrm{~nm}$, respectively. The concentrations of the compounds in GMP were calculated using the calibration lines.

\subsection{Animal Experiments}

BALB/c (three-week-old, male) mice were obtained from Koatech (Seoul, Korea). Male mice were used in this study because the individual estrous cycle in the female mice might result in more variable data than male mice. Moreover, female hormones (estrogen, progesterone) have been reported to promote Th2 activity that affects clinical outcomes in the AD model [21]. Animal studies were conducted according to the protocols approved by the Institutional Animal Care and Use Committee of Dongguk University (IACUC-2020-05). The animals were stabilized for two weeks before the experiments. The mice were divided randomly to five groups ( $\mathrm{n}=7-8$ per group): normal control group (NC), DNCB treatment group (DNCB), DNCB plus $0.1 \%$ of GMP (0.1\% GMP), DNCB plus $1 \%$ of GMP (1\% GMP), DNCB plus $0.1 \%$ DEX (DEX). Figure 1 shows a schematic diagram of the experimental schedule. BALB/c mice were treated topically with $4 \%$ SDS and 1\% DNCB three times per week for one week (sensitization period). The AD-like skin lesions were maintained by topical treatment with $0.3 \%$ DNCB three times per week for five weeks. DNCB, GMP, and DEX were dissolved in a 3:1 mixture of acetone and olive oil. The mice were treated topically with vehicles or drugs $(200 \mu \mathrm{L})$ five times per week for five weeks. The severity of skin lesions was assessed for symptoms of erythema, edema, scale/dryness, and abrasions in the epidermis. The scale for each symptom includes the following: 0 (asymptomatic), 1 (mild), 2 (moderate), and 3 (severe). At the end of the experiment, all mice were sacrificed using isoflurane, and the body weight and spleen weight of each mouse was recorded. The spleen index was defined as the ratio of spleen weight to body weight $(\mathrm{mg} / \mathrm{g})$. For protein expression analysis, skin lesions on the back and prefrontal cortex (PFC) were excised and homogenized using a tissue extraction reagent.

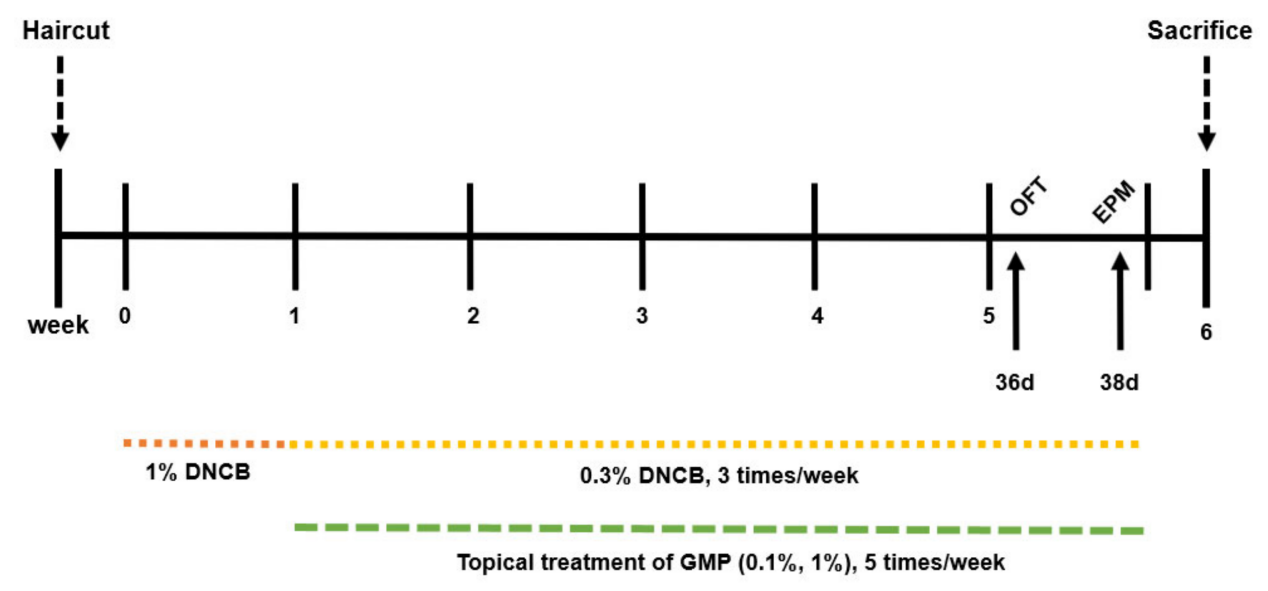

Figure 1. Experimental design for induction of $A D$ and GMP treatment in BALB/c mice. AD, atopic dermatitis; GMP, Gomokpi; DNCB, 2,4-dinitrochlorobenzene; OFT, open field test; EPM, elevated plus maze.

\subsection{Open Field Test (OFT)}

On day 36 of the experiment, an OFT was conducted to evaluate the effects of GMP on locomotor activity in DNCB-treated BALB/c mice. All mice were moved to the test room $1 \mathrm{~h}$ before the experiment for habituation. The mice were placed in the center of an OFT box $(40 \times 40 \times 40 \mathrm{~cm})$ and were allowed to explore freely for $15 \mathrm{~min}$. At the end of each session, the box was wiped with 70\% alcohol to remove the odor. Smart V3.0 software (Panlab Harvard Apparatus, MA, USA) was used to assess the total distances ( $\mathrm{cm})$, distances in the periphery and the center, and mean speeds $(\mathrm{cm} / \mathrm{s})$. 


\subsection{Elevated Plus Maze (EPM)}

On day 38 of the experiment, the EPM was conducted to measure the anxiety-like behaviors in mice. All mice were moved to the test room $1 \mathrm{~h}$ before the experiment for habituation. Each mouse was placed in the center of a plus maze (two opposite open arms and two opposite closed arms) elevated $50 \mathrm{~cm}$ above the floor. The EPM test was conducted for $5 \mathrm{~min}$. At the end of each session, the box was wiped with $70 \%$ alcohol to remove the odor. Smart V3.0 software (Panlab Harvard Apparatus, MA, USA) was used to analyze the number of entries and time spent in the closed and open arms in a 5 min session.

\subsection{Histological Analysis}

The collected dorsal skin samples were fixed in 4\% paraformaldehyde and paraffinembedded. The sections were cut at $5 \mu \mathrm{m}$ and stained with hematoxylin and eosin (H\&E), toluidine blue, and Congo red. The histological observation was conducted using a Lionheart FX Microscope and Gen5 Imager software (Biotek Instruments Inc., Winooski, VT, USA). The epidermal thickness and the number of eosinophils and mast cells were determined in three randomly selected areas per sample.

\subsection{Cell Culture and Treatments}

HaCaT cells (a human keratinocyte cell line) were obtained from KIOM (Daegu, Korea). Raw264.7 cells (a mouse macrophage cell line), EL4 cells (a mouse T lymphoblast cell line), and HMC-1 cells (a human mast cell line) were obtained from the Korean Cell Line Bank (Seoul, Korea). The HaCaT, Raw264.7, and EL4 cells were cultured in DMEM supplemented with $1 \%$ penicillin-streptomycin and $10 \%$ FBS in a humidified environment of $5 \% \mathrm{CO}_{2}$ at $37^{\circ} \mathrm{C}$. The HMC-1 cells were cultured in IMDM supplemented with $10 \%$ FBS, $1 \%$ penicillinstreptomycin, $1.2 \mathrm{mM}$ 1-thioglycerol, in a $5 \% \mathrm{CO}_{2}$ humidified incubator at $37^{\circ} \mathrm{C}$. All cell types were pre-treated with selected concentrations of GMP for $1 \mathrm{~h}$ before stimulation. HaCaT, Raw264.7, and EL4 cells were stimulated with TI (TNF- $\alpha$ and IFN- $\gamma, 10 \mathrm{ng} / \mathrm{mL}$ each), LPS (1 $\mathrm{gg} / \mathrm{mL})$, and PI (PMA $10 \mathrm{ng} / \mathrm{mL}$, ionomycin $100 \mathrm{ng} / \mathrm{mL})$, respectively, for $24 \mathrm{~h}$. The HMC-1 cells were stimulated with SP $(10 \mu \mathrm{M})$ for $48 \mathrm{~h}$.

\subsection{Cell Viability Assay}

The cytotoxic effects of GMP on HaCaT, Raw264.7, EL4, and HMC-1 cells were investigated using a Cell Proliferation Kit II (XTT) (Sigma-Aldrich, Mannheim, Germany). The cells were seeded at a density of $5 \times 10^{4}$ cells /well $(100 \mu \mathrm{L})$ into 96-well plates and cultured for $24 \mathrm{~h}$, and treated with $\operatorname{GMP}(50,100,300$, and $500 \mu \mathrm{g} / \mathrm{mL})$ for another $24 \mathrm{~h}$. Subsequently, XTT solution $(50 \mu \mathrm{L} /$ well) was added and the plates were incubated for $4 \mathrm{~h}$. The optical densities were assessed at $450 \mathrm{~nm}$ (reference wavelength: $650 \mathrm{~nm}$ ) using a microplate reader (Tecan Sunrise, Männedorf, Switzerland).

\subsection{Enzyme-Linked Immunosorbent Assay (ELISA)}

Commercial ELISA kits were used to determine the levels of chemokines and cytokines in cell-cultured media and skin tissue lysates, including TARC and MDC in HaCaT cells, TNF- $\alpha$ in Raw264.7 cells, IL-17 in EL4 cells, VEGF in HMC-1 cells, and IFN- $\gamma$, VEGF, and IL-10 in skin lysates. All procedures were conducted following the manufacturer's instructions. The absorbances were evaluated at $450-540 \mathrm{~nm}$ using a microplate reader (Tecan Sunrise, Männedorf, Switzerland).

\subsection{Statistical Analysis}

All experiments were performed at least three times independently. The data are presented as the means \pm standard errors followed by the statistical significance (Student's t-test for unpaired experiments) with a $p$-value $<0.05$. The Pearson correlation was used to evaluate the correlation between the two different parameters. 


\section{Results}

\subsection{Effect of GMP on Skin Lesions in DNCB-Treated BALB/c Mice}

As shown in Figure 2A,B, after applying DNCB to the back skin for six weeks, the clinical skin symptoms of the DNCB group was significantly more severe than the NC group. In contrast, the skin scores were reduced significantly in the $0.1 \%$ GMP and 1\% GMP treated groups compared to the DNCB group (Figure 2A,B). In addition, the spleen index was reduced significantly in the DNCB group compared to the NC group, which was significantly lower in the GMP-treated groups (Figure $2 \mathrm{C}$ ). The topical application of GMP decreased DNCB-induced epidermal hyperplasia significantly in BALB/c mice (Figure 2D). Toluidine blue and Congo red staining results showed that eosinophil and mast cell infiltrations in the skin lesions were less severe in the $0.1 \%$ GMP and 1\% GMP groups than in the DNCB group (Figure 2D).

(A)

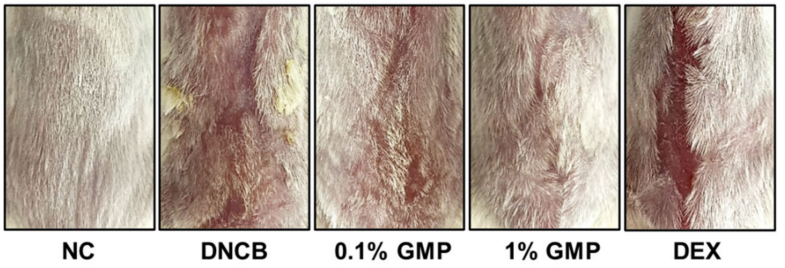

(B)

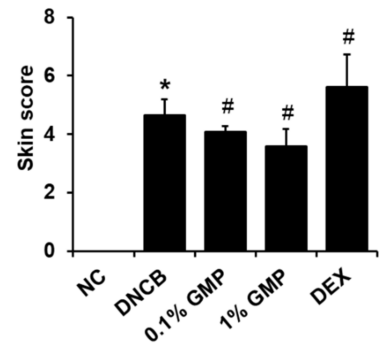

(C)

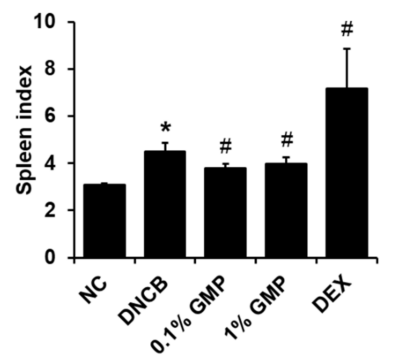

(D)

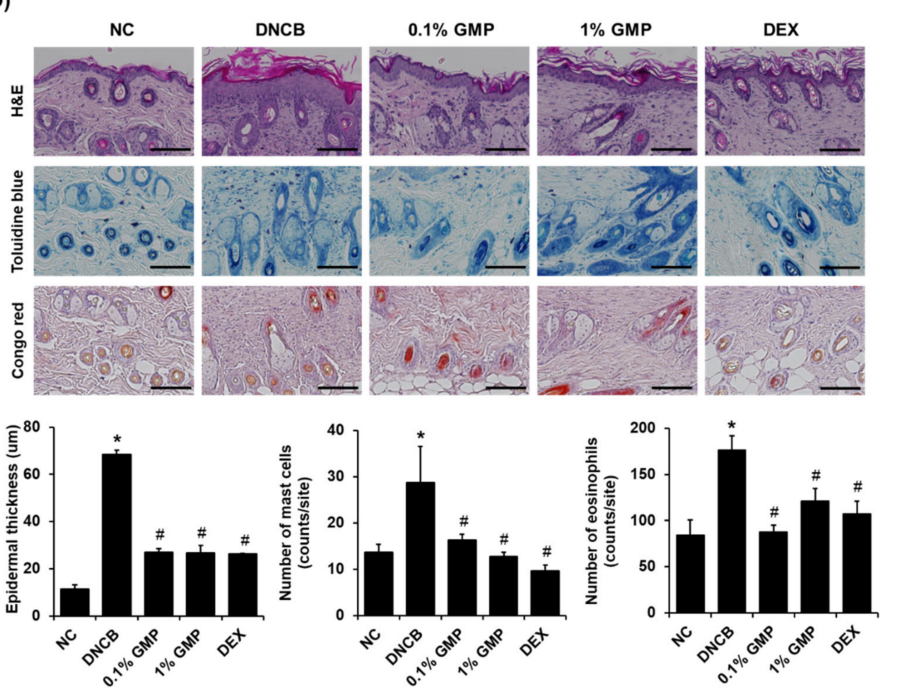

Figure 2. Effect of GMP on AD-like symptoms in DNCB-treated BALB/c mice. (A) Images of dorsal skin lesions from each group were taken at the end of the experiment. (B) The total skin score of dorsal skin lesions (C) Spleen index was measured. (D) Histological and immunohistochemical staining of dorsal skin samples. Scale bar: $100 \mu \mathrm{m}$. Data represent the means \pm SDs. ${ }^{*} p<0.05$ compared to the NC group, \# $p<0.05$ compared to the DNCB group. AD, atopic dermatitis; GMP, Gomokpi; DEX, dexamethasone; DNCB, 2,4-dinitrochlorobenzene. 
3.2. Effect of GMP on Serum IgE Levels and Inflammatory Cytokine Levels in Skin Lesions in $D N C B$-Treated BALB/c Mice

The effects of GMP on the levels of serum $\operatorname{IgE}$ and inflammatory cytokines in the skin tissues were evaluated using an enzyme-linked immunosorbent assay (ELISA). The results show that the serum IgE level was significantly increased in the DNCB group, compared with the NC group (Figure 3A). In contrast, treatment with 1\% GMP reduced the IgE level in the serum significantly. The levels of IFN- $\gamma$, VEGF, and IL-10 in the skin lysates were significantly higher in the DNCB group than in the NC group. On the other hand, these increases were lowered by treatment with GMP (Figure 3B-D).

(A)
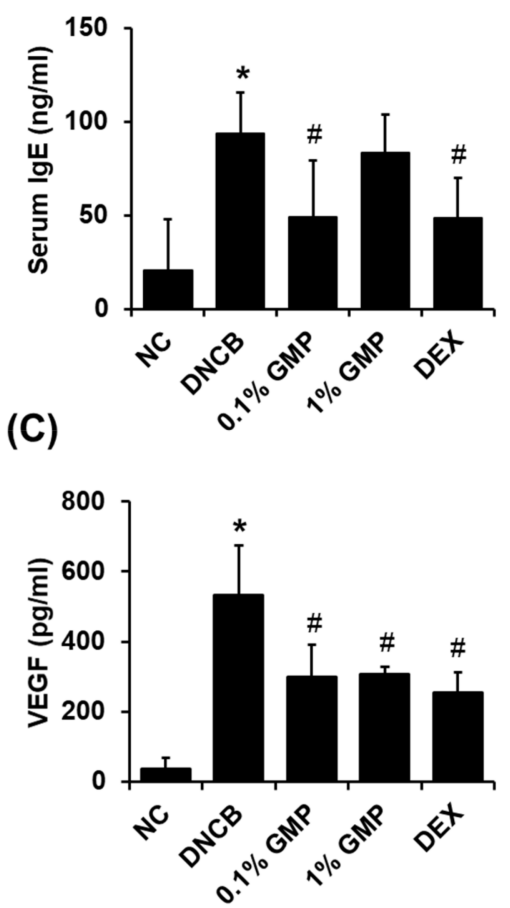

(B)
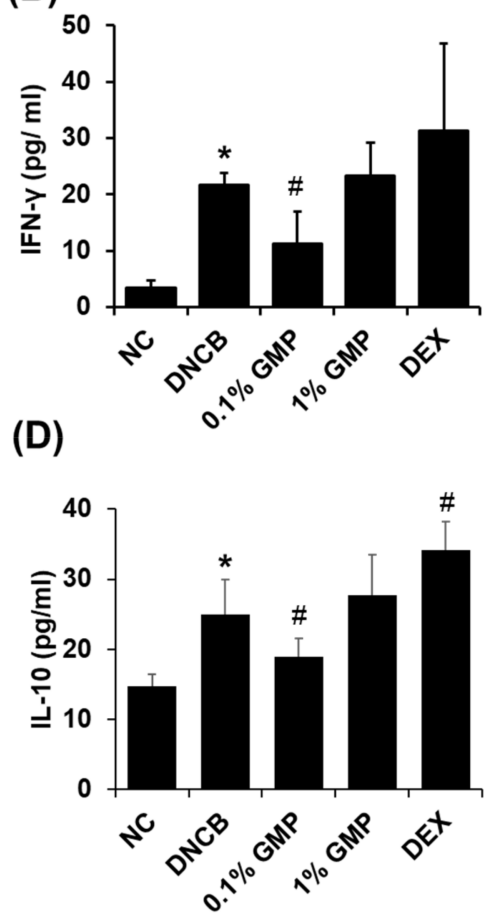

Figure 3. Effect of GMP on serum IgE and inflammatory cytokines. Serum IgE and cytokine levels were evaluated by ELISA. (A) Serum IgE level. (B-D) Levels of inflammatory cytokine IFN- $\gamma$, VEGF, and IL-10 in the skin lesions. Data represent the means \pm SDs. ${ }^{*} p<0.05$ vs. the NC group, $\# p<0.05$ vs. the DNCB group.

\subsection{Effect of GMP on the Behavioral Changes in DNCB-Treated BALB/c Mice}

The effects of GMP on locomotor activity and anxiety-like behavior were evaluated using OFT and EPM tests. In the OFT test, the DNCB group showed a significant increase in the total distance and distance traveled in the center compared to the NC group. The $0.1 \%$ GMP and 1\% GMP groups showed a significant decrease compared to the DNCB group. The mean speed was also higher in the DNCB group than the NC group and lower in the GMP treatment groups (Figure 4A,B). The DNCB group showed a moderate increase in the distance traveled in open arms of EPM, but there was no significant difference between the NC and DNCB groups (Figure 4C,D). In contrast, compared to the DNCB group, the distance in the open arms was significantly reduced in the 0.1\% GMP and 1\% GMP groups. The distance traveled in closed arms and the mean speed of the DNCB group were not significantly different from the NC group, and the GMP treatment did not have any effects (Figure 4C,D). 
(A)

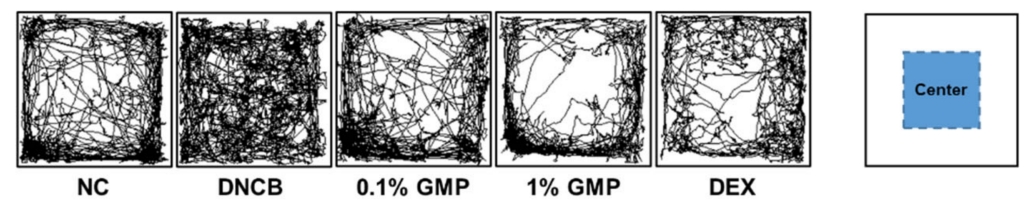

(B)
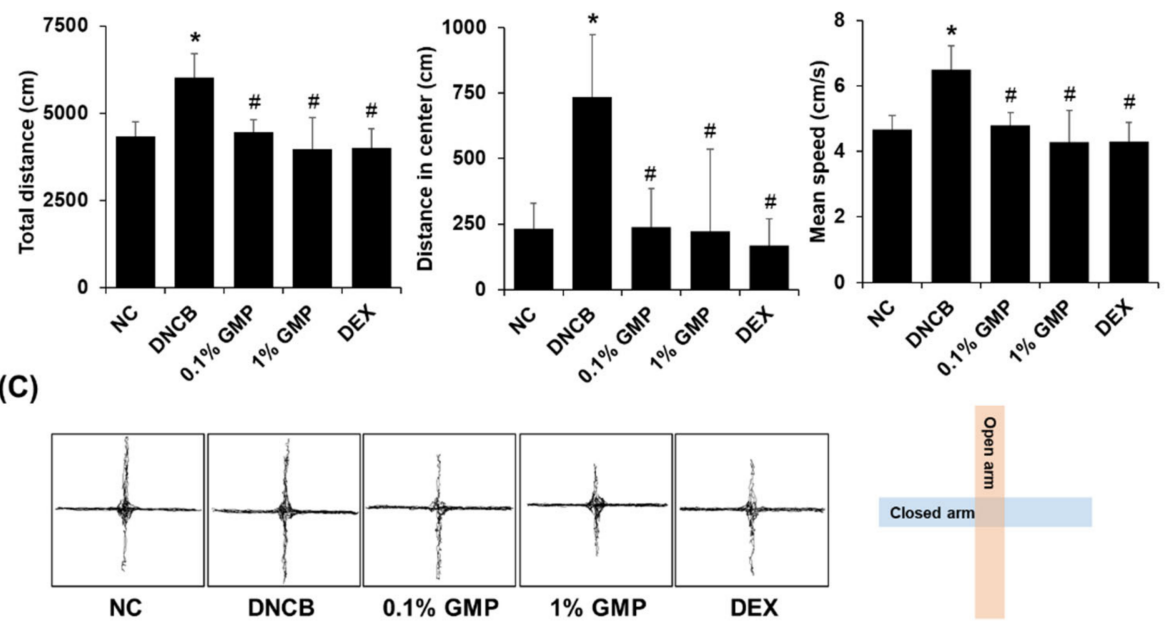

(D)
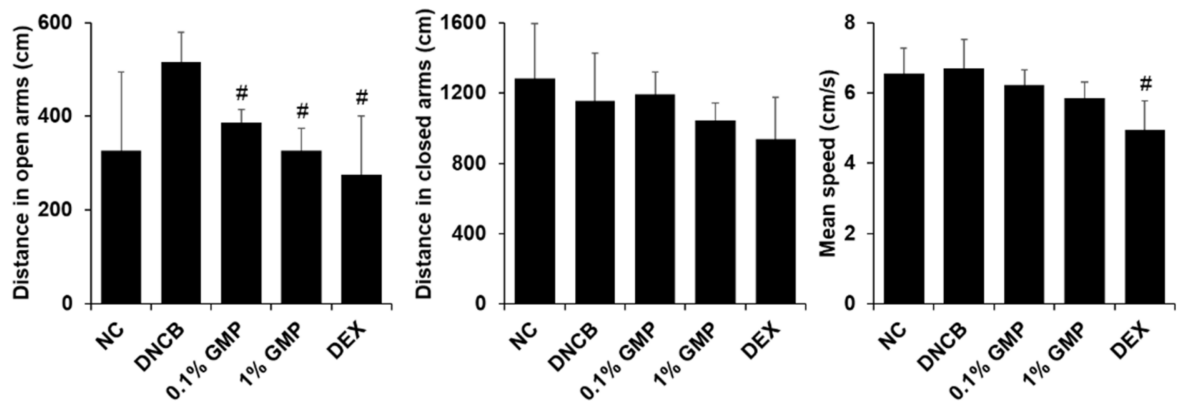

Figure 4. Effect of GMP on behavioral changes in DNCB-treated BALB/c mice. (A) Representative tracking images of each group in the OFT. (B) Total distance, distance in center, and mean speed in the OFT were assessed on day 36. (C) Representative tracking images of each group in the EPM. (D) Distance in open arms, closed arms, and mean speed in the EPM were assessed on day 38. Data represent the means \pm SDs. ${ }^{*} p<0.05$ vs. the NC group, $\# p<0.05$ vs. the DNCB group.

\subsection{Effect of GMP on Neuroinflammation in DNCB-Treated BALB/c Mice}

ELISA showed that the levels of TNF- $\alpha$ and IL-1 $\beta$ in the PFC were increased in the DNCB group compared to the NC group. The GMP treatment reduced TNF- $\alpha$ levels significantly but did not affect the IL-1 $\beta$ levels (Figure 5A). IL-6 expression was similar in the NC group and the DNCB group, and the 1\% GMP group decreased significantly compared to the DNCB group (Figure 5A). The relationship between the total distance in the OFT and the expression levels of the inflammatory cytokines in the PFC were analyzed further to determine if the hyperactivity behavior correlates with neuroinflammation. The total distance in the OFT showed a positive correlation with TNF- $\alpha$ levels $\left(\mathrm{R}^{2}=0.3594\right.$, $p<0.0001$ ) (Figure 5B). 
(A)

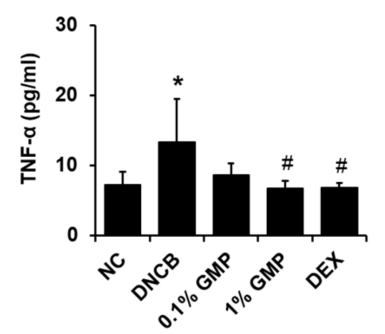

(B)

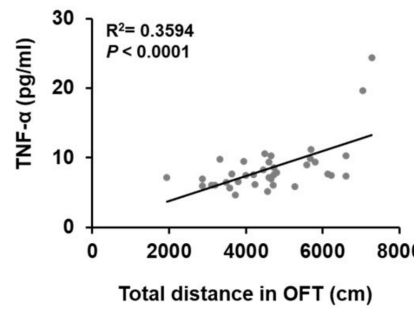

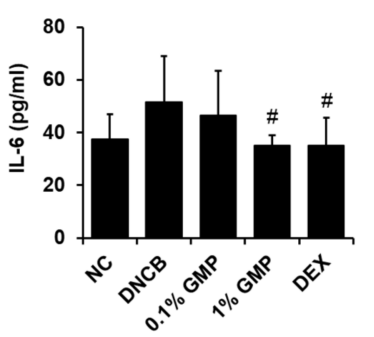
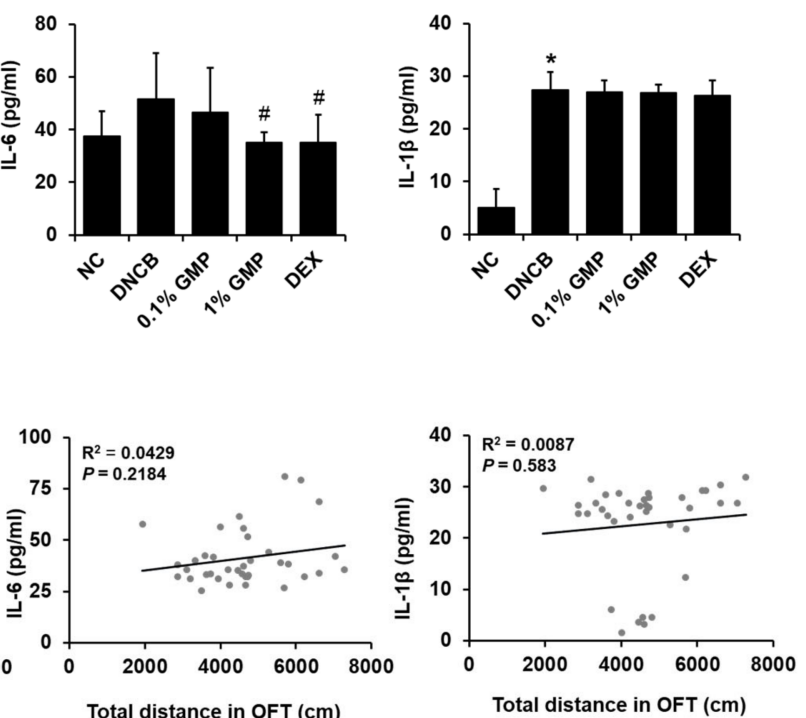

Figure 5. Effect of GMP on the inflammatory cytokine levels in the PFC in DNCB-treated BALB/c mice. (A) Inflammatory cytokines TNF- $\alpha$, IL-6, and IL-1 $\beta$ levels in the PFC area of the brain. (B) Correlation between inflammation cytokine and total distance in OFT. Data represent the means \pm SDs. ${ }^{*} p<0.05$ vs. the NC group, $\# p<0.05$ vs. the DNCB group.

\subsection{Effect of GMP on Inflammatory Responses In Vitro}

HaCaT, HMC-1, EL4, and Raw264.7 cells were used to investigate the anti-inflammatory effects of GMP in vitro. The XTT assays showed that GMP had cytotoxic effects at $300-500 \mu \mathrm{g} / \mathrm{mL}$ (Figure $6 \mathrm{~A}, \mathrm{C}, \mathrm{E}, \mathrm{G}$ ). Therefore, the doses of 50 and $100 \mu \mathrm{g} / \mathrm{mL}$ of GMP were selected for further experiments. The production levels of TARC and MCD after TI stimulation in HaCaT cells were measured to examine the effect of GMP on Th2 chemokines. The production of TARC was increased significantly in the TI group compared to the Con group, and GMP reduced TARC production in a dose-dependent manner (Figure 6B). On the other hand, the MDC levels were similar in groups (Figure 6B). In Raw264.7 cells, LPS stimulation increased the production of TNF- $\alpha$, which was decreased by the GMP pretreatment (Figure 6D). Similarly, preincubation with GMP also lowered the levels of IL-17 in PI-stimulated EL4 cells and decreased the levels of VEGF in the SP-stimulated HMC-1 cells (Figure 6F,H).

(A)

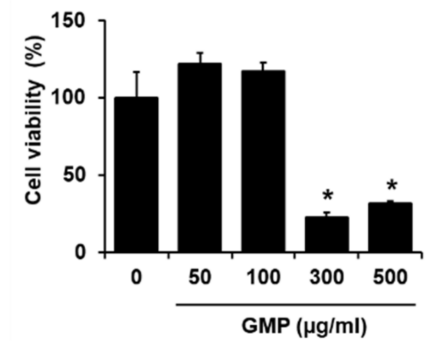

(B)

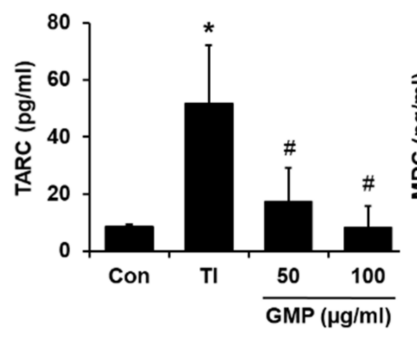

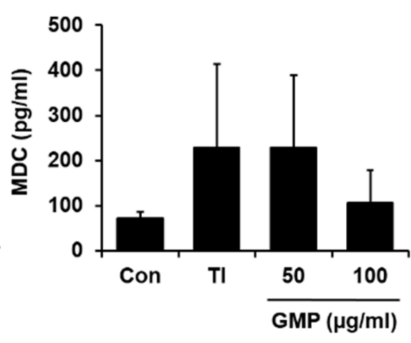

Figure 6. Cont. 
(C)

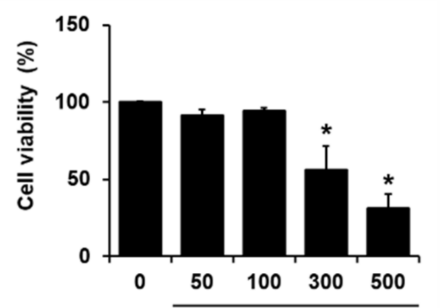

(E)

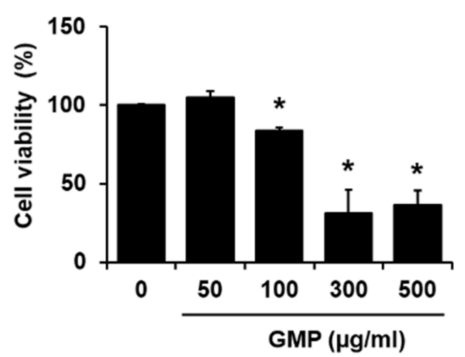

(G)

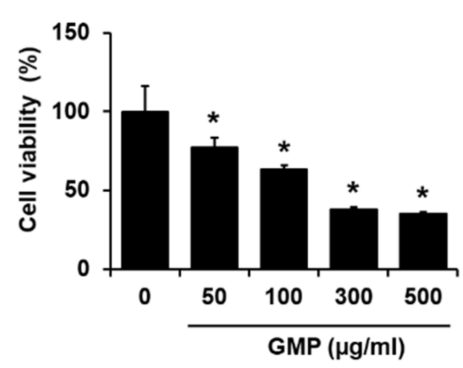

(D)

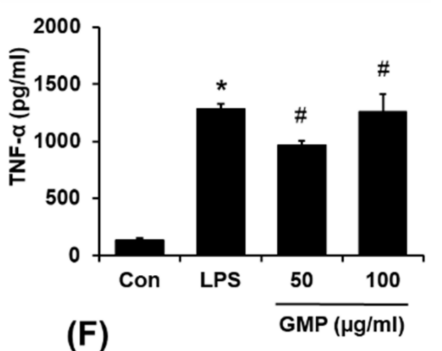

(F)

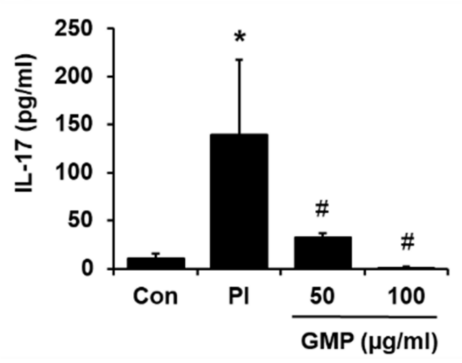

(H)

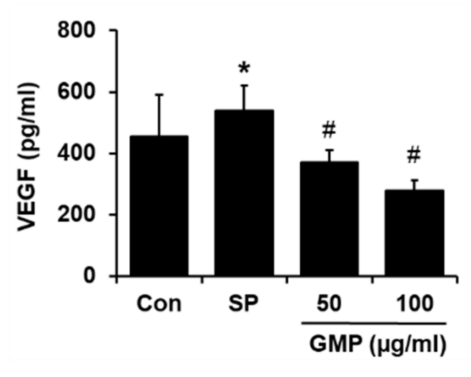

Figure 6. Effect of GMP on the inflammatory responses in vitro. (A) Effect of GMP on cell viability of HaCaT cells. (B) Effect of GMP on TARC and MDC production in TI-stimulated HaCaT cells. (C) Effect of GMP on cell viability of Raw264.7 cells. (D) Effect of GMP on TNF- $\alpha$ level in LPSstimulated Raw264.7 cells. (E) Effect of GMP on cell viability of EL4 cells. (F) Effect of GMP on IL-17 level in PI-stimulated EL4 cells. (G) Effect of GMP on cell viability of HMC-1 cells. (H) Effect of GMP on VEGF production in SP-stimulated HMC-1 cells. Data represent the means \pm SDs. ${ }^{*} p<0.05$ vs. the Con, $\# p<0.05$ vs. the TI-treated cells, $\# p<0.05$ vs. the LPS-treated cells, $\# p<0.05$ vs. the PI-treated cells. \# $p<0.05$ vs. the SP-treated cells.

\subsection{Quantification of Chemical Constituents in GMP}

The bioactive compounds in GMP were quassin and picrasin B (Figure 7A) [18]. Figure 7B presents chromatograms of two standard compounds. Quassin, but not picrasin B, was detected in the GMP extract (Figure 7C). The retention time of quassin was $12.733 \mathrm{~min}$, and the concentration of quassin in GMP was $2.963 \mathrm{mg} / \mathrm{g}$. 
(A)

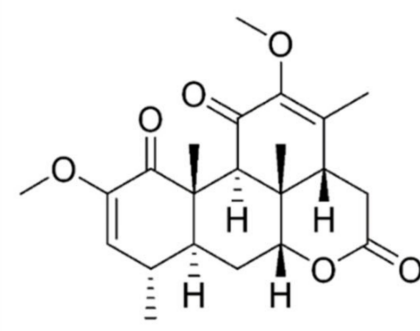

(B)

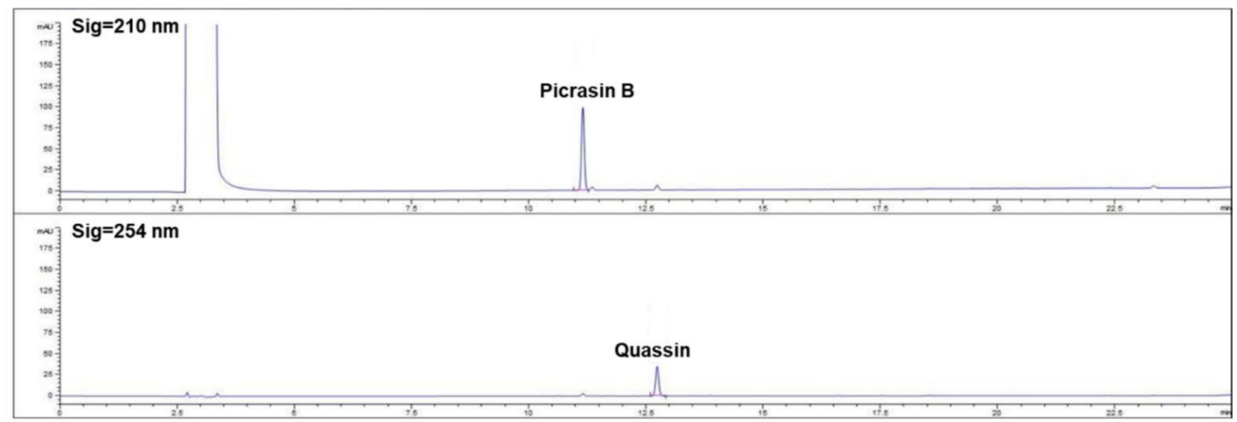

(C)

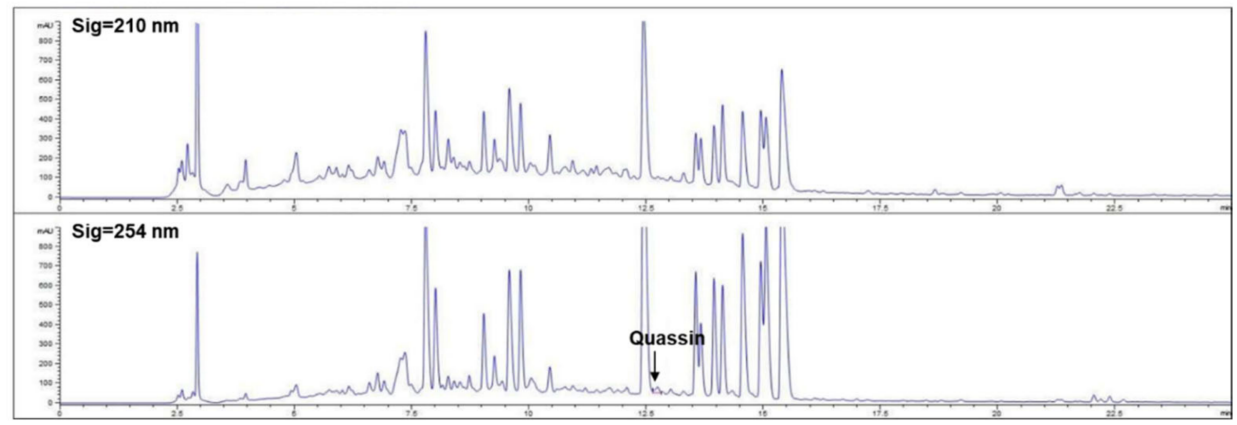

Figure 7. Analysis of chemical constituents of GMP by HPLC. (A) Structures of picrasin B and quassin. HPLC chromatograms of the standard compounds (B) and GMP (C).

\section{Discussion}

$\mathrm{AD}$ is a common chronic inflammatory skin disease with an incidence from $3-20 \%$ in children and $2-5 \%$ in adults worldwide [22,23]. Accumulating evidence suggests that AD is associated with various neuropsychiatric comorbidities, such as ADHD, anxiety, and depression, which reduce the quality of life of AD patients significantly [24]. Recent studies indicated that $\mathrm{AD}$ exhibits a transient association with the later onset of ADHD and approximately $7 \%$ of total AD patients suffer from ADHD symptoms $[25,26]$. Therefore, managing both skin symptoms and psychiatric disorders might be a more effective approach for $\mathrm{AD}$ treatment. This study revealed the inhibitory effects of GMP on AD-skin inflammation and AD-induced hyperactivity behavior in DNCB-treated mice, suggesting its potential in the drug development for AD.

DNCB-induced cutaneous inflammation in mice was reported as an appropriate model for AD studies [27]. In this study, the topical application of DNCB to the back skin of BALB/c mice induced AD-like symptoms, such as redness, dryness, and excoriation. On the other hand, the GMP treatment could ameliorate these symptoms in AD mice significantly. Epidermal hyperplasia and infiltration of inflammatory cells in skin lesions are typical characteristics of $\mathrm{AD}$ [28]. These results indicated that the topical treatment of GMP alleviated DNCB-induced epidermal thickening and infiltration of mast cells and eosinophils in skin lesions. The roles of mast cells in allergic disease, including AD, 
were well characterized in previous studies [29,30]. Mast cells are generally activated by binding IgE to FceRI receptors on the cell surface, and activated mast cells can secrete a range of inflammatory molecules, such as histamine, TNF- $\alpha$, and VEGF [31]. Interestingly, GMP could decrease both IgE and VEGF levels in DNCB-treated mice. Pretreatment with GMP also reduced SP-induced production of VEGF in HMC-1 cells, suggesting the inhibitory effects of GMP on the mast cell response in AD. In addition to mast cells, macrophages, another innate immune cell type, play a pivotal role in developing AD. The accumulation of macrophages is observed in acute and chronic AD inflamed skin. In the early stages of inflammation, macrophages have pro-inflammatory functions, such as antigen presentation and the production of inflammatory cytokines [32]. These results suggest that GMP inhibited the LPS-induced TNF- $\alpha$ production in Raw264.7 macrophages. These results suggest the suppressive effects of GMP on the innate immune system for the treatment of AD symptoms.

$\mathrm{T}$ lymphocytes, particularly $\mathrm{T}$ helper cells, play crucial roles in the pathogenesis of $\mathrm{AD}$ [33]. The infiltration of $\mathrm{CD} 4+\mathrm{T}$ cells into the dermis was observed in $\mathrm{AD}$ skin lesions [34]. In the early phase of $\mathrm{AD}, \mathrm{Th} 2$ cells are prominent infiltrates in lesional skin. The recruitment of Th2 lymphocytes into $\mathrm{AD}$ lesions might be triggered by several chemokines, such as MDC and TARC, mainly produced by keratinocytes [35]. A previous study reported that the levels of these Th2 chemokines were elevated in AD patients compared to healthy subjects [36]. Infiltrated Th2 cells secrete many inflammatory cytokines, including IL-4, IL-5, and IL-10, to promote skin inflammation and skin barrier disruption in AD [37]. In this study, GMP reduced the expression of IL-10 in skin lesions of AD mice and suppressed the production of TARC in TI-stimulated HaCaT keratinocytes, suggesting the effects of GMP on the Th2 response in AD. In addition to Th2 cells, Th1 and Th17 cells, as well as their effector cytokines are involved in the progression of AD. Th1 cells can produce various cytokines, such as IFN- $\gamma$, TNF- $\alpha$, and IL-2, while Th17 cells are well known for the production of IL-17 [38]. IL-17 triggers the Th2 response and B cell differentiation to promote an inflammatory response in $\mathrm{AD}[39,40]$. In the current study, the GMP treatment decreased the levels of IFN- $\gamma$ in AD mice and reduced the production of IL-17 in PIstimulated EL4 cells, suggesting that GMP can also modulate the activities of Th1/Th17 cells to improve the AD symptoms.

ADHD is one of the most prevalent neuropsychiatric comorbidities in AD patients. The severity of $\mathrm{AD}$ may result in emotional and behavioral problems, contributing to an increased incidence of ADHD [41,42]. In this study, AD mice exhibited ADHD-like symptoms, as inferred from the increased total distance travel and speed in the OFT. The hyperactivity in $\mathrm{AD}$ mice was also indicated by a moderate increase in the distance in open arms of the EPM. In contrast, treatment with GMP could attenuate the hyperlocomotion behavior in $\mathrm{AD}$ mice, indicating the beneficial effects of GMP on psychiatric comorbidities of AD. Neuroinflammation plays an important role in the development of ADHD [43]. Several immune cells, such as microglia, astrocytes, and mast cells are involved in the development of neuroinflammation by secreting inflammatory cytokines, such as TNF- $\alpha$, IL-6, and IL-1 $\beta$ [44,45]. In the present study, the level of TNF- $\alpha$ in PFC was increased in the AD mice, and the TNF- $\alpha$ level positively correlated with hyperactivity behavior. This was reduced by the GMP treatment, suggesting that GMP improved behavioral changes in AD mice by inhibiting neuroinflammation.

Topical steroids are commonly used to treat $\mathrm{AD}$ because they can reduce inflammation and itching symptoms in dermatitis [46]. On the other hand, long-term skin treatment of these steroids might result in various adverse effects such as skin atrophy, impaired skin barrier function, and drug resistance [47]. The results showed that some biomarkers were improved by the DEX treatment, but the overall clinical severity was worsened in the DEX group compared to the GMP group. The GMP group did not have any side effects, even after long-term treatment, highlighting the safety of GMP for AD treatment.

HPLC showed that quassin is a major component of GMP. A previous study indicated the anti-inflammatory activity of quassin by suppressing the expression of inflammatory 
molecules, including iNOS2, TNF- $\alpha$, IL-10, and IL-12 in murine macrophages [48]. In addition, quassin exerted neuroprotective effects by increasing the viability of SH-SY5Y neuroblastoma cells under $\mathrm{H}_{2} \mathrm{O}_{2}$ stimulation [49]. These findings suggest that quassin might improve the therapeutic effects of GMP against DNCB-induced skin inflammation and behavioral changes in mice.

This study still had some limitations that can be improved in future studies. Several other behavioral tests for evaluation of other psychiatric symptoms in AD mice, such as depression (sucrose preference test, tail suspension test) should be conducted for a more detailed conclusion about AD-associated psychiatric disorders in the mouse model. The effects of GMP on signaling pathways related to AD can also be examined to investigate the underlying mechanisms. Therefore, further studies should be performed to provide more scientific evidence for the efficacy of GMP for AD treatment.

\section{Conclusions}

GMP alleviated the AD-like skin inflammation and hyperlocomotion activity in DNCBtreated BALB/c mice. The effects of GMP behavioral abnormalities might be through inhibiting TNF- $\alpha$ production in the PFC. GMP also showed the anti-inflammatory effects in vitro by suppressing the production of inflammatory cytokines and chemokines in HaCaT keratinocytes, Raw264.7 macrophages, EL4 T cells, and HMC-1 mast cells. These findings suggest that GMP could be useful for the treatment of AD by modulating inflammatory responses and comorbid behavioral changes.

Author Contributions: Conceptualization, H.-M.S. and I.-J.Y.; investigation, M.-J.C.; formal analysis, M.-J.C. and L.T.H.N.; writing-original draft preparation, M.-J.C. and L.T.H.N.; writing-reviewing and editing, H.-M.S. and I.-J.Y. All authors have read and agreed to the published version of the manuscript.

Funding: This research was funded by the National Research Foundation of Korea (NRF) funded by the Ministry of Education (grant number NRF-2019R1F1A1059856).

Institutional Review Board Statement: The study was conducted according to the guidelines of the Declaration of Helsinki, and approved by the Institutional Review Board (or Ethics Committee) of Institutional Animal Care and Use Committee of Dongguk University (protocol code IACUC-2020-05, 03 January 2020).

Informed Consent Statement: Not applicable.

Data Availability Statement: The data presented in this study are available in this article.

Conflicts of Interest: The authors declare no conflict of interest. The funders had no role in the design of the study; in the collection, analyses, or interpretation of data; in the writing of the manuscript, or in the decision to publish the results.

\section{References}

1. Shin, J.E.; Jeon, Y.H.; Yang, H.J.; Pyun, B.Y. Comparison of Clinical Severity and Laboratory Results between Atopic and Non-atopic Eczema in Children. Pediatr. Allergy Respir. Dis. 2008, 18, $219-227$.

2. Kang, W.S.; Jeoung, S.M.; Xu, X.; Lee, J.E.; Ryu, S.H.; Ahn, D.H. Anti-Atopic Effect of DNCB-Induced Mouse in Chondrus canaliculatus Ethanol Extracts. J. Korean Soc. Food Sci. Nutr. 2019, 49, 482-483.

3. Ahn, J.-Y.; Im, L.-R.; Kim, J.-H.; Park, J.-H.; Kim, D.-K.; Lee, Y.-M. Effects of Rumecis Radix Water Extract on Development of Atopic Dermatitis in BALB/c Mice. Korean J. Pharmacogn. 2009, 40, 218-223.

4. Chen, Y.; Xian, Y.F.; Loo, S.; Lai, Z.; Chan, W.Y.; Liu, L.; Lin, Z.X. Huang-Lian-Jie-Du extract ameliorates atopic dermatitis-like skin lesions induced by 2,4-dinitrobenzene in mice via suppression of MAPKs and NF-кB pathways. J. Ethnopharmacol. 2020, 249, 112367. [CrossRef] [PubMed]

5. Walsh, L.J.; Trinchieri, G.; Waldorf, H.A.; Whitaker, D.; Murphy, G.F. Human dermal mast cells contain and release tumor necrosis factor alpha, which induces endothelial leukocyte adhesion molecule 1. Proc. Natl. Acad. Sci. USA 1991, 88, 4220-4224. [CrossRef] [PubMed]

6. Ahn, K. Role of Mast Cells in Allergic Inflammation and Innate Immunity. Korean J. Pediatr. 2004, 47, 1137-1141.

7. Chieosilapatham, P.; Kiatsurayanon, C.; Umehara, Y.; Trujillo-Paez, J.V.; Peng, G.; Yue, H.; Nguyen, L.T.H.; Niyonsaba, F. Keratinocytes: Innate immune cells in atopic dermatitis. Clin. Exp. Immunol. 2021, 204, 296-309. [CrossRef] [PubMed] 
8. Hänel, K.H.; Cornelissen, C.; Lüscher, B.; Baron, J.M. Cytokines and the skin barrier. Int J. Mol. Sci 2013, 14, 6720-6745. [CrossRef]

9. Yaghmaie, P.; Koudelka, C.W.; Simpson, E.L. Mental health comorbidity in patients with atopic dermatitis. J. Allergy Clin. Immunol. 2013, 131, 428-433. [CrossRef]

10. Strom, M.A.; Fishbein, A.B.; Paller, A.S.; Silverberg, J.I. Association between atopic dermatitis and attention deficit hyperactivity disorder in U.S. children and adults. Br. J. Dermatol. 2016, 175, 920-929. [CrossRef]

11. Zhou, R.Y.; Wang, J.J.; Sun, J.C.; You, Y.; Ying, J.N.; Han, X.M. Attention deficit hyperactivity disorder may be a highly inflammation and immune-associated disease (Review). Mol. Med. Rep. 2017, 16, 5071-5077. [CrossRef] [PubMed]

12. Leffa, D.T.; Torres, I.L.S.; Rohde, L.A. A Review on the Role of Inflammation in Attention-Deficit/Hyperactivity Disorder. Neuroimmunomodulation 2018, 25, 328-333. [CrossRef] [PubMed]

13. Costa-Pinto, F.A.; Basso, A.S.; Britto, L.R.; Malucelli, B.E.; Russo, M. Avoidance behavior and neural correlates of allergen exposure in a murine model of asthma. Brain Behav. Immun. 2005, 19, 52-60. [CrossRef] [PubMed]

14. Shaw, P.; Lerch, J.; Greenstein, D.; Sharp, W.; Clasen, L.; Evans, A.; Giedd, J.; Castellanos, F.X.; Rapoport, J. Longitudinal mapping of cortical thickness and clinical outcome in children and adolescents with attention-deficit/hyperactivity disorder. Arch. Gen. Psychiatry 2006, 63, 540-549. [CrossRef]

15. Buske-Kirschbaum, A.; Trikojat, K.; Tesch, F.; Schmitt, J.; Roessner, V.; Luksch, H.; Rösen-Wolff, A.; Plessow, F. Altered hypothalamus-pituitary-adrenal axis function: A relevant factor in the comorbidity of atopic eczema and attention deficit/hyperactivity disorder? Psychoneuroendocrinology 2019, 105, 178-186. [CrossRef]

16. Jung, Y.S.; Eun, C.S.; Jung, Y.T.; Kim, H.J.; Yu, M.H. Anti-Inflammatory Effects of Picrasma Quassioides (D.DON) BENN Leaves Extracts. Korean Soc. Life Sci. 2013, 23, 629-636.

17. Jin, Y.-S.; Yin, Y.; Shin, T.-H.; Sa, J.-H.; Wang, M.-H. Studies for Component Analysis and Biological Evaluation in Picrasma quassioides (D.Don) Benn. Extract. Korean J. Pharmacogn. 2006, 37, 37-41.

18. Lee, J.; Gong, Y.-X.; Jeong, H.; Seo, H.; Xie, D.-P.; Sun, H.-N.; Kwon, T. Pharmacological effects of Picrasma quassioides (D. Don) Benn for inflammation, cancer and neuroprotection (Review). Exp. Ther. Med. 2021, 22, 1357. [CrossRef]

19. Shin, N.R.; Shin, I.S.; Jeon, C.M.; Hong, J.M.; Oh, S.R.; Hahn, K.W.; Ahn, K.S. Inhibitory effects of Picrasma quassioides (D.Don) Benn. on airway inflammation in a murine model of allergic asthma. Mol. Med. Rep. 2014, 10, 1495-1500. [CrossRef]

20. Ryu, I.-H.; Cho, H.-B.; Kim, S.-B.; Seo, Y.-J.; Choi, C.-M. The inhibitory effect of Picrasmae Lignum on inflammatory responses. Korean J. Obstet. Gynecol. 2011, 24, 1-14.

21. Kanda, N.; Hoashi, T.; Saeki, H. The Roles of Sex Hormones in the Course of Atopic Dermatitis. Int. J. Mol. Sci. 2019, 20, 4660. [CrossRef] [PubMed]

22. Silverberg, J.I.; Barbarot, S.; Gadkari, A.; Simpson, E.L.; Weidinger, S.; Mina-Osorio, P.; Rossi, A.B.; Brignoli, L.; Saba, G.; Guillemin, I. Atopic dermatitis in the pediatric population: A cross-sectional, international epidemiologic study. Ann. Allergy Asthma Immunol. 2021, 126, 417-428.e412. [CrossRef] [PubMed]

23. Barbarot, S.; Auziere, S.; Gadkari, A.; Girolomoni, G.; Puig, L.; Simpson, E.; Margolis, D.; de Bruin-Weller, M.; Eckert, L. Epidemiology of atopic dermatitis in adults: Results from an international survey. Allergy 2018, 73, 1284-1293. [CrossRef] [PubMed]

24. Paller, A.; Jaworski, J.C.; Simpson, E.L.; Boguniewicz, M.; Russell, J.J.; Block, J.K.; Tofte, S.; Dunn, J.D.; Feldman, S.R.; Clark, A.R.; et al. Major Comorbidities of Atopic Dermatitis: Beyond Allergic Disorders. Am. J. Clin. Dermatol. 2018, 19, 821-838. [CrossRef]

25. Xu, Y.-C.; Wang, J.-P.; Zhu, W.-J.; Li, P. Childhood atopic dermatitis as a precursor for developing attention deficit/hyperactivity disorder. Int. J. Immunopathol. Pharmacol. 2020, 34, 2058738420962902. [CrossRef] [PubMed]

26. Thomas, R.; Sanders, S.; Doust, J.; Beller, E.; Glasziou, P. Prevalence of attention-deficit/hyperactivity disorder: A systematic review and meta-analysis. Pediatrics 2015, 135, e994-e1001. [CrossRef] [PubMed]

27. Kim, J.; Lee, J.; Shin, S.; Cho, A.; Heo, Y. Molecular Mechanism of Atopic Dermatitis Induction Following Sensitization and Challenge with 2,4-Dinitrochlorobenzene in Mouse Skin Tissue. Toxicol. Res. 2018, 34, 7-12. [CrossRef]

28. Nomura, T.; Honda, T.; Kabashima, K. Multipolarity of cytokine axes in the pathogenesis of atopic dermatitis in terms of age, race, species, disease stage and biomarkers. Int. Immunol. 2018, 30, 419-428. [CrossRef]

29. Kawakami, T.; Ando, T.; Kimura, M.; Wilson, B.S.; Kawakami, Y. Mast cells in atopic dermatitis. Curr. Opin. Immunol. 2009, 21, 666-678. [CrossRef]

30. Amin, K. The role of mast cells in allergic inflammation. Respir. Med. 2012, 106, 9-14. [CrossRef]

31. Krystel-Whittemore, M.; Dileepan, K.N.; Wood, J.G. Mast Cell: A Multi-Functional Master Cell. Front. Immunol. 2016, 6, 620. [CrossRef] [PubMed]

32. Kasraie, S.; Werfel, T. Role of Macrophages in the Pathogenesis of Atopic Dermatitis. Mediators Inflamm. 2013, $2013,942375$. [CrossRef] [PubMed]

33. Biedermann, T.; Skabytska, Y.; Kaesler, S.; Volz, T. Regulation of T Cell Immunity in Atopic Dermatitis by Microbes: The Yin and Yang of Cutaneous Inflammation. Front. Immunol. 2015, 6, 353. [CrossRef] [PubMed]

34. Leung, D.Y.M.; Bieber, T. Atopic dermatitis. Lancet 2003, 361, 151-160. [CrossRef]

35. van den Bogaard, E.H.; Tjabringa, G.S.; Joosten, I.; Vonk-Bergers, M.; van Rijssen, E.; Tijssen, H.J.; Erkens, M.; Schalkwijk, J.; Koenen, H. Crosstalk between keratinocytes and T cells in a 3D microenvironment: A model to study inflammatory skin diseases. J. Investig. Dermatol. 2014, 134, 719-727. [CrossRef] 
36. Nakazato, J.; Kishida, M.; Kuroiwa, R.; Fujiwara, J.; Shimoda, M.; Shinomiya, N. Serum levels of Th2 chemokines, CCL17, CCL22, and CCL27, were the important markers of severity in infantile atopic dermatitis. Pediatr. Allergy Immunol. 2008, 19, 605-613. [CrossRef] [PubMed]

37. Wang, A.X.; Xu Landén, N. New insights into T cells and their signature cytokines in atopic dermatitis. IUBMB Life 2015, 67, 601-610. [CrossRef] [PubMed]

38. Orciani, M.; Campanati, A.; Caffarini, M.; Ganzetti, G.; Consales, V.; Lucarini, G.; Offidani, A.; Di Primio, R. T helper (Th)1, Th17 and Th2 imbalance in mesenchymal stem cells of adult patients with atopic dermatitis: At the origin of the problem. Br. J. Dermatol. 2017, 176, 1569-1576. [CrossRef]

39. Nakajima, S.; Kitoh, A.; Egawa, G.; Natsuaki, Y.; Nakamizo, S.; Moniaga, C.S.; Otsuka, A.; Honda, T.; Hanakawa, S.; Amano, W.; et al. IL-17A as an inducer for Th2 immune responses in murine atopic dermatitis models. J. Investig. Dermatol. 2014, 134, 2122-2130. [CrossRef]

40. Milovanovic, M.; Drozdenko, G.; Weise, C.; Babina, M.; Worm, M. Interleukin-17A promotes IgE production in human B cells. J. Investig. Dermatol. 2010, 130, 2621-2628. [CrossRef]

41. Romanos, M.; Gerlach, M.; Warnke, A.; Schmitt, J. Association of attention-deficit/hyperactivity disorder and atopic eczema modified by sleep disturbance in a large population-based sample. J. Epidemiol. Community Health 2010, 64, 269-273. [CrossRef] [PubMed]

42. Buske-Kirschbaum, A.; Schmitt, J.; Plessow, F.; Romanos, M.; Weidinger, S.; Roessner, V. Psychoendocrine and psychoneuroimmunological mechanisms in the comorbidity of atopic eczema and attention deficit/hyperactivity disorder. Psychoneuroendocrinology 2013, 38, 12-23. [CrossRef] [PubMed]

43. Dunn, G.A.; Nigg, J.T.; Sullivan, E.L. Neuroinflammation as a risk factor for attention deficit hyperactivity disorder. Pharmacol. Biochem. Behav. 2019, 182, 22-34. [CrossRef]

44. Song, Y.; Lu, M.; Yuan, H.; Chen, T.; Han, X. Mast cell-mediated neuroinflammation may have a role in attention deficit hyperactivity disorder (Review). Exp. Ther. Med. 2020, 20, 714-726. [CrossRef] [PubMed]

45. Corona, J.C. Role of Oxidative Stress and Neuroinflammation in Attention-Deficit/Hyperactivity Disorder. Antioxidants 2020, 9, 1039. [CrossRef]

46. Hong, J.E.; Park, M.-c.; Kang, S.-J.; Yang, G.-J.; Jo, E.H. New Interpretation on MyeonGu of Baekho-Tang Text of Shanghanlun through Case Reports; The Physiological Society of Korean Medicine and the Society of Pathology in Korean Medicine: Seoul, Korea, 2020.

47. Lim, K.-M.; Song, J.-H.; Choi, J.-H.; Kim, J.-H.; Jung, M.-Y.; Park, S.-Y. Effects of Three Types of GagamBangpungtongseongsan(Except Talcum) on the Atopic Dermatitis in Mice. J. Korean Med. Ophthalmol. Otolaryngol. Dermatol. 2020, $33,1-26$.

48. Bhattacharjee, S.; Gupta, G.; Bhattacharya, P.; Mukherjee, A.; Mujumdar, S.B.; Pal, A.; Majumdar, S. Quassin alters the immunological patterns of murine macrophages through generation of nitric oxide to exert antileishmanial activity. J. Antimicrob. Chemother. 2009, 63, 317-324. [CrossRef]

49. He, C.; Wang, Y.; Yang, T.; Wang, H.; Liao, H.; Liang, D. Quassinoids with Insecticidal Activity against Diaphorina citri Kuwayama and Neuroprotective Activities from Picrasma quassioides. J. Agric. Food Chem. 2020, 68, 117-127. [CrossRef] 